\title{
Lockin thermography to monitor propagation of delamination in CFRP composites during compression tests
}

\author{
by C. Toscano*, A. Riccio**, F. Camerlingo***, C. Meola ${ }^{\star \star \star \star}$
}

${ }^{*}$ C.I.R.A. - Italian Aerospace Research Centre, via Maiorise sn, 81043 Capua (CE) Italy

PhD at DIAS - Aerospace Engineering Dept., University of Naples Federico II, via Claudio, 21, (NA), Italy c.toscano@cira.it

** DIAM - Aerospace and Mechanics Department, Second University of Naples, via Roma 29, 81031 Aversa (CE) Italy, aniello.riccio@unina2.it

${ }^{* \star \star}$ AleniaAermacchi, via dell'Aeronautica, 80038, Pomigliano d'Arco (NA), Italy, fcamerlingo@alenia.it

$\star * \star \star$ Department of Aerospace Engineering (DIAS), University of Naples Federico II, Via Claudio, 21, (NA), Italy, carmeola@unina.it

\begin{abstract}
The presence of delamination is a major problem in CFRP laminated panels and so, it is of great concern to both the academic and the aeronautical industrial worlds. Indeed delamination can strongly affect the material strength and, sometimes, can cause their breaking up in service. The aim of this work is to monitor the propagation of delamination during typical applied axial loadings. Therefore, a panel with an embedded delamination was manufactured, and subjected to compression test, while the delamination propagation was being monitored by lockin thermography. The obtained results were used to corroborate the ones coming from numerical computation.
\end{abstract}

\section{Introduction}

Carbon Fibre Reinforced Plastics (CFRP) composites are nowadays largely employed in the aeronautical industry, to fabricate primary and secondary aircraft parts. The CFRP appealing is related to the possibility to minimize structural weight and hence fuel consumption, leading to a significant reduction of costs and $\mathrm{CO}_{2}$ emissions. Production processes [1] involve several parameters; therefore, a non-optimized procedure could led to final parts with enclosed intrinsic defects, such as delamination. This kind of defect could also be caused by low energy impacts due to tools drop during maintenance or debris rising during aircraft take-off and landing. Low impact energies can cause barely visible damages, but also severe and complex delamination buried in the structure bulk material. This makes components more vulnerable to failure by buckling under a combination of compression, shear and in-plane bending [2]. Buckling loads can be substantially compromised by the presence of damage (up to $30 \%$ in the case of delamination ([3], [4]).

Big efforts have been devoted to the development of effective non-destructive evaluation (NDE) techniques for damage assessment and continuous monitoring of the structural integrity ([5], [6]), especially for aircraft and spacecraft parts. The use of the most conventional NDE ([7], [8]) techniques such as ultrasonic C-scan, x-ray, thermography [9] and eddy current is generally limited as they require structural components of complex geometry to be taken out of service during the time needed for post-damage inspection. For continuous and in situ monitoring of real structures, development of new methods, or upgrading of the existing ones, is under way. One of the oldest methods is based on surface-bonded resistive foil strain gauges, but, they are less effective for monitoring the interior delamination. Techniques able to detect unseen damage, preferably in situ, are conceived as structural health monitoring systems (SHM), often based on acoustic emission, which detects elastic waves emitted during the development of damage when a structure is loaded ([9]. They can be easily integrated into composite structures to produce the so-called smart composite structures.

Owing to research studies, embedded fibre optic sensors are very promising ([12]-[14]). They perform in the same way being either non-embedded sensors in terms of failure stresses, or resistive foil strain gauges in tension and compression, although there are stresses and strain concentrations around the embedded fibre optic sensor [15]. Some of the limits of all types of smart structures are related to the need to be located near the region where damage occurs, due to the expected local and/or global changes in strength and stiffness. In addition such smart structures represent in themselves a modification of the original material.

In this work, a method to monitor the damage evolution is addressed. In particular, the attention is focused on a common NDE technique such as lockin thermography ([16]-[18]) to be used during loading tests. This thermal wave based technique, recently promoted as certified method for non destructive testing of aeronautical components, has been taken into account, especially for its contactless aspect, rapidity of the obtained results, and its suitability for on field applications. Lockin thermography is nowadays commonly used to check the integrity of the structures beyond a testing campaign, such as impact testing, or fatigue testing and after thousands compression loading cycles [19]. In the present work, the same NDE technique is used during the action of a compression loading in order to observe the evolution of a simulated defect under specific testing conditions. 
So an ad hoc panel with an embedded delamination was prepared and, hence, subjected to a compression loading test. The applied force was increased by discrete steps, in order to carry out, at each step, a complete lock-in test to search for any modification of the embedded delamination until the breakage of the panel.

The obtained phase images allow observing delamination spreading and onset of the buckling deformation. All the experimental results were compared with the results obtained through numerical modelling.

The goal of this work is to share the expertises of research center, academic and industry to gain novel information on the propagation of delamination in composites.

\section{Panel concept and buckling model prediction}

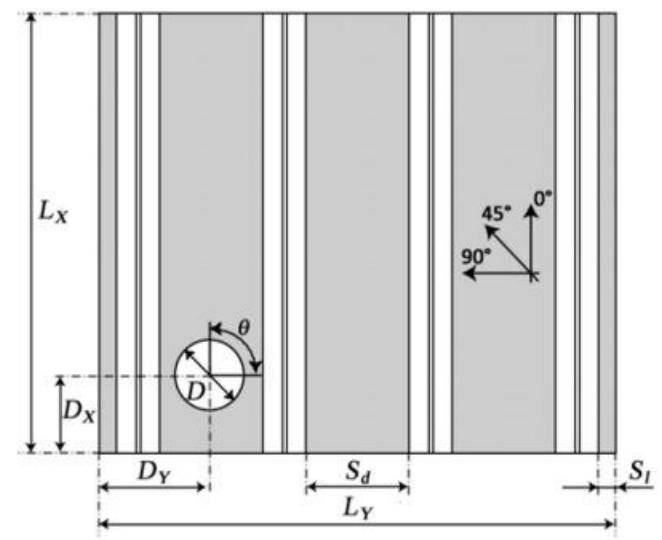

Fig. 1. Schematic of the tested panel and the position of the induced delamination.

A panel with stringers and with an embedded delamination (fig.1) was analysed under compression loading. The presence of delamination, in real life, can onset as consequence of manufacturing defects or of low velocity impacts; it can grow under service loads promoting the structural collapse. The presence of delamination acts as a very dangerous defect because, under compression load, it causes buckling of the layers with loss of material strength (fig. 2).
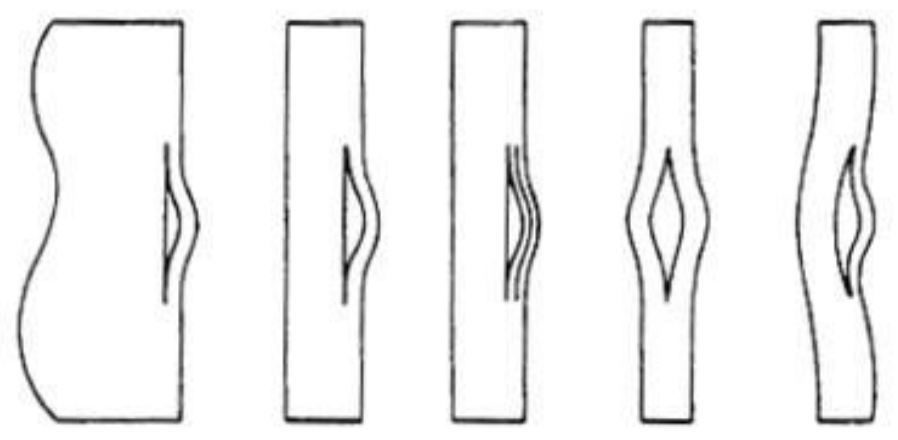

Fig. 2. Sketch of possible delamination buckling.

It is well known, from the fracture mechanics of composites, that Strain Energy Release Rate rules the propagation of cracks. For each fracture mode (opening mode I, forward shear mode II and parallel shear mode III) a strain energy release rate can be defined.

Once the starting crack propagation values for the basic fracture modes are known, from ad hoc experiments, it is possible to predict mixed modes of crack propagation in laminates by means of suitable criteria such as the power law criterion:

$$
\left(\frac{G_{I}}{G_{I_{C}}}\right)^{\alpha}+\left(\frac{G_{I I}}{G_{I I_{C}}}\right)^{\beta}+\left(\frac{G_{I I I}}{G_{I I I_{C}}}\right)^{\gamma}=E_{d} \geq 1
$$

The satisfaction of relation (1) is assumed to be the necessary condition for crack propagation. 
The delamination growth model was implemented in our finite element code by means of interface fracture elements. These elements use the Virtual Crack Closure Technique (VCCT) to calculate the Strain Energy Release Rate along the delamination front. The VCCT is based on the consideration that the Strain Energy released by a crack growing from length $a$ to $a+\Delta a$ is equal to the amount of work required to close the same crack from $a+\Delta a$ to $a$ ([20][23]).

The interface fracture elements are placed between the 8 noded solid elements at the delamination front in the delaminated region. The rest of the panel has been modelled by 8 noded shell elements. The connections between solid and shell elements have been performed by adopting contact elements based on Multi-Points-Constraints (MPC) kinematical relations. The same approach has been used to created shell-to-shell connections between the skin and the stringer feet. The resulting Finite Elements Method (FEM) based model is shown in figure 3.

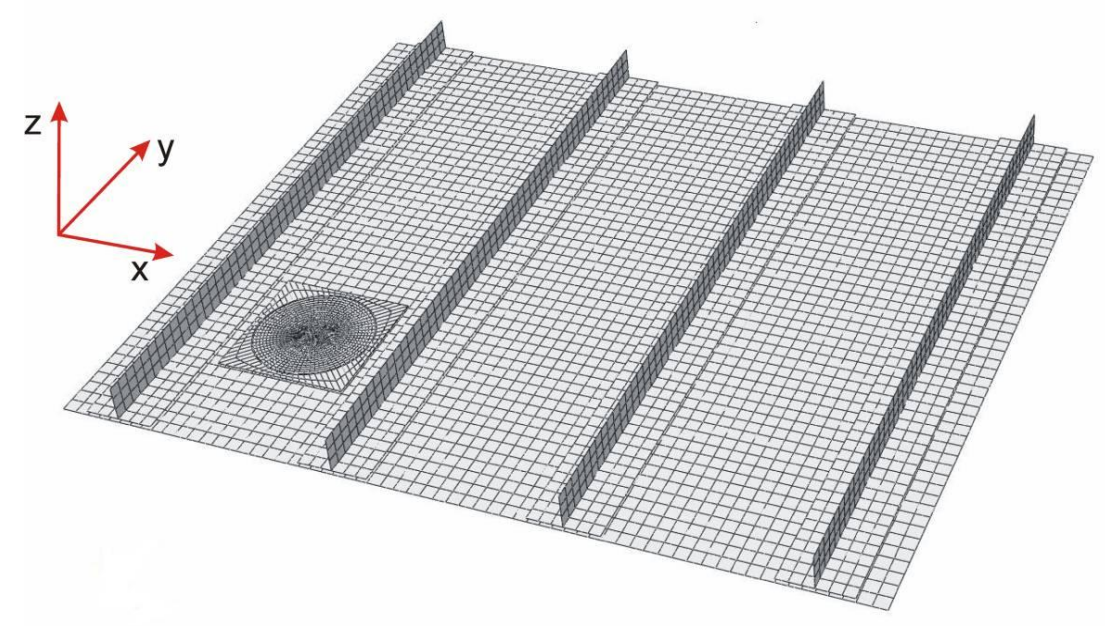

Fig. 3. The mesh used for the model. The part simulating the embedded delamination can be seen in the left lower side.

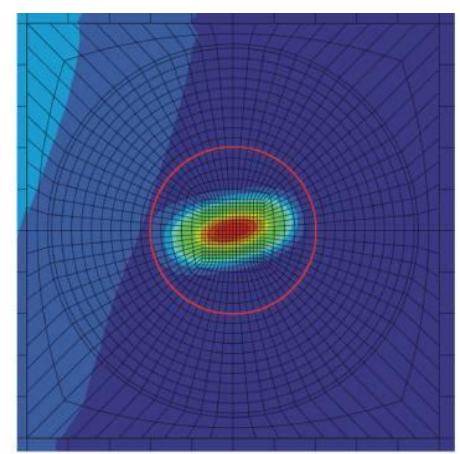

a)

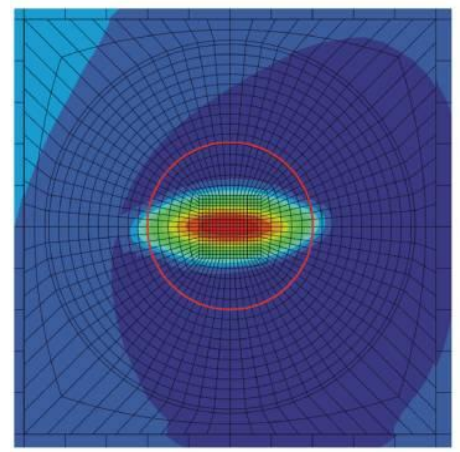

c)

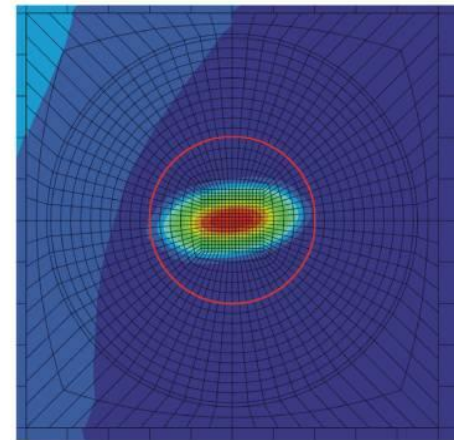

b)

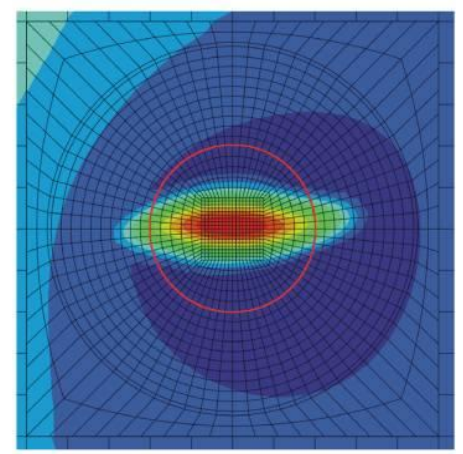

d)

Fig. 4. Evolution of the Buckling of the delaminations, during compression loading. 
In the model, the compression loading was applied along the $y$ direction in figure 3 , and the start and the evolution of the buckling were analysed, until the panel failure. In fig. 4 results, in terms of delamination propagation, are shown which were obtained by applying increasing loadings according to a geometrically non-linear FEM analysis. The buckling deformation spread can be appreciated with respect the perimeter of the initial circular embedded delamination, which is highlighted by a red circle. In figure 4.a, representative of the deformation obtained by loading the structure up to $300 \mathrm{kN}$, the delamination buckling phenomenon is clearly noticeable. In figure 4.b, corresponding to an applied compressive load of $450 \mathrm{kN}$, the deformation reaches the boundary of the delaminated area. By increasing the load (respectively, up to $500 \mathrm{kN}$ in fig. 4.c, and up to $600 \mathrm{kN}$ in fig. 4.d), the deformation of the bucked sub-laminate extends beyond the initial delaminated area demonstrating the propagation of the delamination.

The delamination spreading is characterized by an elliptical shape whose major axis has a preferential direction which is almost perpendicular to the one of the applied compression loading.

\section{Experimental}

The tested panel was obtained by overlaying 24 plies $600 \mathrm{~mm} \times 500 \mathrm{~mm}$ carbon/epoxy pre-preg laminas and was reinforced with four stringers. To simulate induced delamination two overlapped teflon disks, $40 \mathrm{~mm}$ in diameter, were inserted within the plies stacking sequence ( see fig. 1).

Before the starting of the compression test, the panel was non destructively analysed by a standard lockin test. This allowed to detect the teflon disk and to measure its diameter without any applied loadings. In addition, the test parameters for the subsequent tests were established.

Both the halogen lamp (for the thermal stimulation) and the thermal camera (FLIR SC5500) were put in front of the panel; on the viewed panel side delamination was under the third ply with respect to the framed surface (fig. 5).

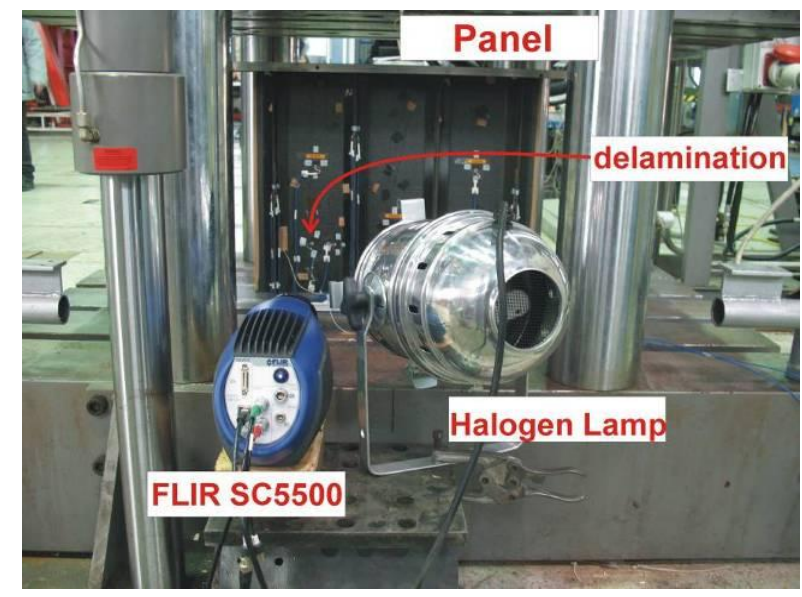

Fig. 5. Set up for non destructive lockin thermography tests .

With the stimulation frequency of $0.3 \mathrm{~Hz}$ the best phase contrast was obtained. This allowed to easily measure the delamination diameter.

On the phase image, which is shown in figure 6 , the disk is remarked by a blue dot line; it can be noticed that the teflon disk appears as a not perfect circle, but with lack of a sector in the right side as indicated by the blue arrow in figure. Such a non circular shape has to be ascribed to manufacturing problems.

The distance $(\sim 170 \mathrm{~mm})$ among the two stringers corresponds to 252 pixels on the thermal camera screen, then the conversion factor for pixels vs. $\mathrm{mm}$ is known. The diameter of the disk is about $41 \mathrm{~mm}$.

The optimal parameters used for all the following tests are resumed in the table 1.

Table1. Lockin tests parameters.

\begin{tabular}{|c|c|}
\hline Halogen lamp stimulation frequency & $.3 \mathrm{~Hz}$ \\
\hline Frequency rate (thermal camera) & $11 \mathrm{~Hz}$ \\
\hline Integration Time (thermal camera) & \\
\hline
\end{tabular}




\begin{tabular}{|c|c|}
\hline & $205 \mu \mathrm{s}$ \\
\hline Acquired frames & 110 \\
\hline
\end{tabular}
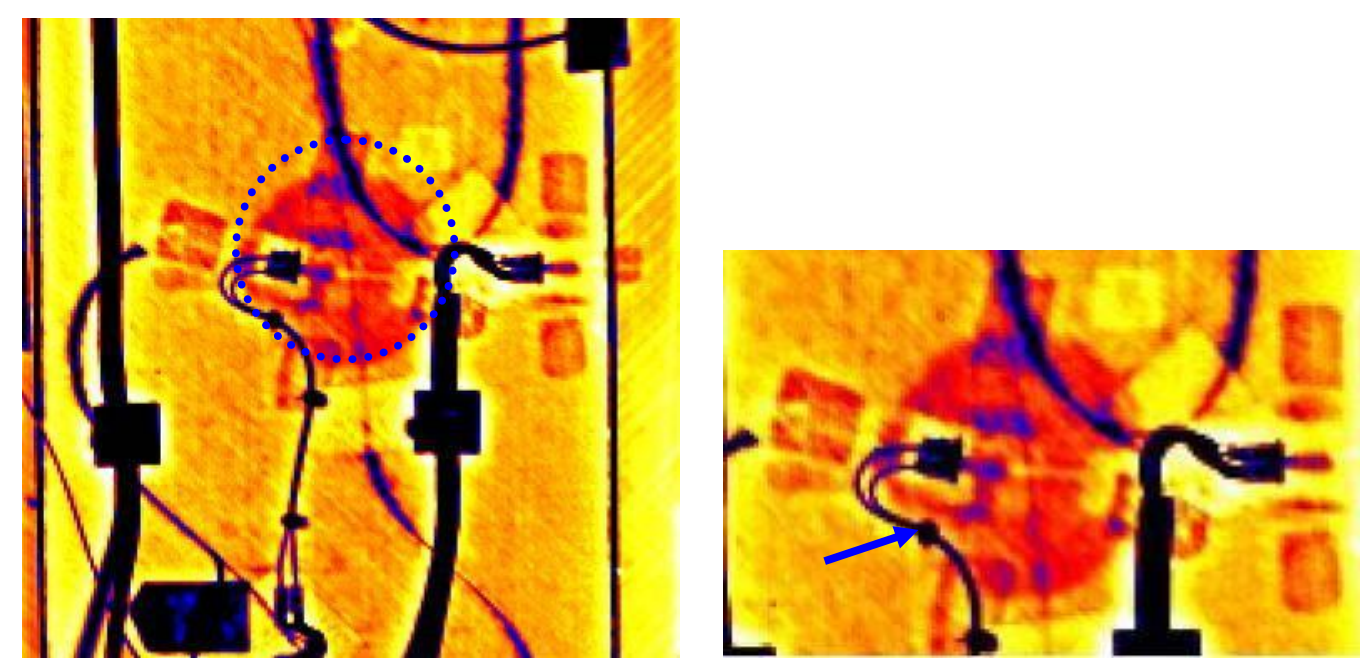

Fig. 6. Phase image taken at $0.3 \mathrm{~Hz}$ stimulation frequency. On the right a zoom of the embedded delamination can be seen. The embedded delamination is not perfectly circular, indeed it seems that lower half left part is missing (see the blue arrow). 


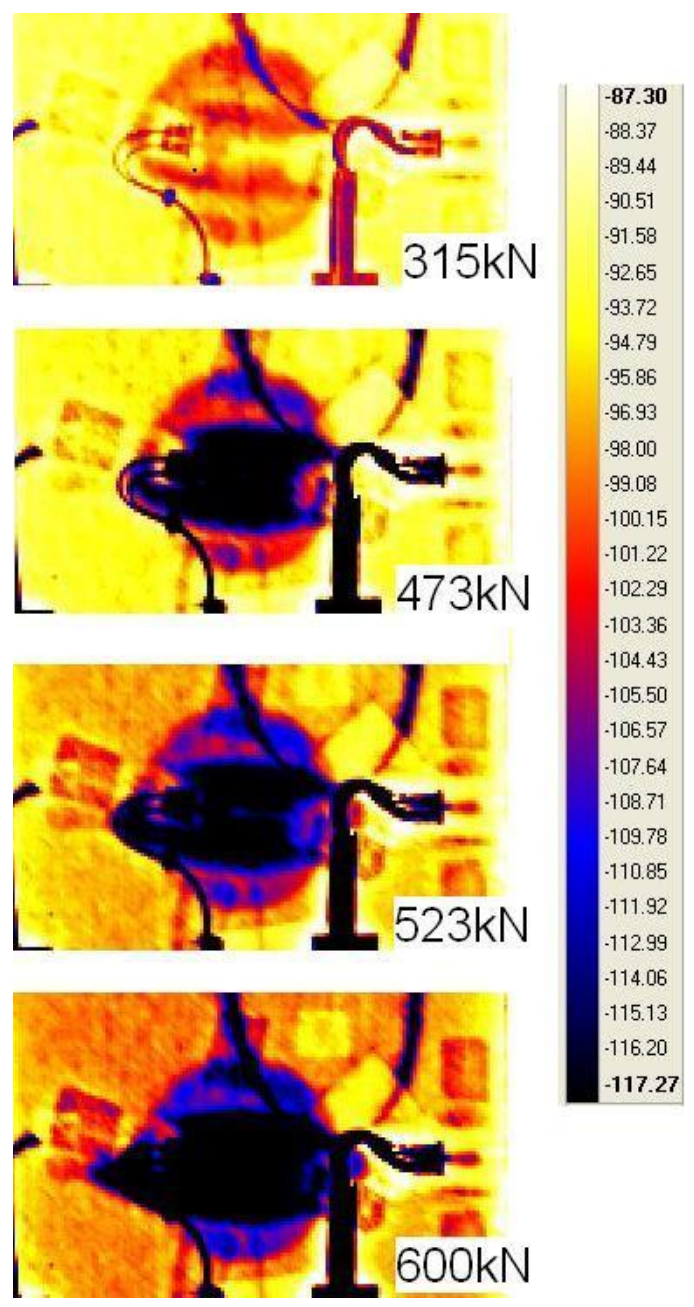

Fig. 7. Phase images obtained at increasing compression loading. The buckling deformation and its propagation can be appreciated. The scale is referred to the phase angle expressed in degrees.

After the initial lockin test (for the embedded delamination detection), the composite panel was properly constrained in the MTS servohydraulic fixture (fig. 5), and a compression loading was applied progressively through 13 steps until the panel breaking.

At each step, correspondent to a certain load value, the progressive compression was stopped, then a lockin test was carried out in order to monitor any variation of the delamination, specifically its shape and boundary dimensions. After that, the compression load restarted again until the successive step loading was reached, and so on. The starting load was $L=100 \mathrm{kN}$ and then it was increased up to $L=600 \mathrm{kN}$; when the load exceeded this last value, the panel broke.

Some of the phase images, obtained at increasing compression loads, are shown in figure 7 . In the phase map obtained for $\mathrm{L}=315 \mathrm{kN}$, the onset of the deformation can be appreciated through the presence of the two lighter horizontal lines symmetrically placed in the central part of the embedded delamination. This happens because the deformation ellipse is beginning to growth, which corresponds, owing to numerical results, to the situation of fig. 4 a. At $\mathrm{L}=473 \mathrm{kN}$ it seems that the ellipse has reached the perimeter of the embedded delamination as foreseen in fig. $4 \mathrm{~b}$. For increasing the compression load, the deformation propagates in the horizontal direction inducing propagation of the delamination as it is appreciable in fig. 7 for $L=523 \mathrm{kN}$ and $\mathrm{L}=600 \mathrm{kN}$. The latter results are in agreement with those shown in fig. $4 c$ and $d$, provided by the numerical model.

Unfortunately, the presence of the strain gauges cables just over the lateral perimeter of the teflon disk has forbidden the possibility to detect, experimentally, the start of the delamination propagation. Indeed the propagation became appreciable just only when it come through the cables. The horizontal diameter measured at $\mathrm{L}=523 \mathrm{kN}$ is almost $49 \mathrm{~mm}$, and it enlarges to about $54 \mathrm{~mm}$ at L=600kN.

The application of lockin thermography during the test has allowed to monitor not only the delamination propagation but also the onset and the growing of the deformation. By comparing the images in the figure 7, with the one obtained without any loading (fig. 6), it can be noticed that not only the buckling deformation but also the deformation of the panel surrounding the teflon disk can be deduced. By the phase images, any displacement in the direction orthogonal to the panel surface are represented with different colours i.e. different phase values. The surface of the panel seems to 
go firstly a little bit out of plane (before $L=523 \mathrm{kN}$ compression loading is reached) in such a way that it is getting far from the infrared camera, whereas it moves in the opposite direction for increasing the loading.

At last, the delamination spreading appears as characterized by an elliptical shape with the major axis direction orthogonal to the one of the applied loading and, in addition, it has the same slope in both phase images and numerical output.

\section{Conclusion}

A CFRP composite panel with an embedded delamination was subjected to a compression loading test by using a servo-hydraulic MTS machine. The applied force was increased progressively through 13 steps, in order to allow performing lockin tests at each step for monitoring the propagation of the induced delamination.

The detection of the delamination propagation onset was not at all achieved due to the masking effect of the strain gauges cables. In fact, we began to observe the delamination propagation when it overpassed the cables. In addition, both onset and growing up of the buckling were observed. By comparing the phase images obtained under load (figure 7), with the one obtained without any loading (fig. 6), it is possible to deduce the deformation of the panel surrounding the teflon disk. It is worth noting that, by comparing the phase images taken at the different compression loadings, which were all obtained by using the same stimulation frequency, differences in phase values, are due to the displacement of the panel in the orthogonal direction. The surface of the panel seems to be subjected to different small deformations, getting firstly far from the IR camera, and then moving in the opposite direction once an increasing loading is applied. These deformations are coherent with the ones schematically represented in fig. 2.

This would be a starting point for future investigations in order to enhance the role of lockin thermography from a simple defect checker to a device able to monitor the defects evolution during static mechanical testing of CFRP composites.

\section{REFERENCES}

[1] Meola C., Toscano C., "NonDestructive Evaluation of Carbon Fiber Reinforced Polymers with Ultrasonics and Infrared Thermography: an overview on historical steps and Patents" MATS vol. 5, No.1, 2012

[2] Greenhalgh E., Singh S., Nilsson K. F., "Mechanisms and modelling of delamination growth and failure of carbon-fiber reinforced skin-stringer panels" ASTM Special Technical Publication, 1383: 49-71, 2000

[3] Abrate S., "Impact on Laminated Composite Materials", Applied Mechanics Review, vol. 47, 11, pp. 517-544, 1994

[4] Greenhalgh E., Meeks C., Clarke A., Thatcher J., "The effect of defects on the performance of post-buckled CFRP stringer-stiffened panels". Composites Part A: Applied Science and Manufacturing, vol. 34 (7), pp. 623633, 2003

[5] Reid S. R., Zhou G., "Impact Behaviour of Fibre-reinforced Composite Materials and Structures", Woodhead Publishing, Cambridge, 2000

[6] Culshaw B., "Optical fibres in NDT: a brief review of applications" NDT Int. 8, pp. 265-273, 1985

[7] http://ntrs.nasa.gov/archive/nasa/casi.ntrs.nasa.gov/20090014807_2009014230.pdf

[8] Beine C., Boller C., Netzelmann U., Porsch F., Ramanan S.V., Schulze, M., Bulavinov A., Heuer H., "NDT for CFRP Aeronautical Components A Comparative Study", Proceedings of NDT in Aerospace, November 22-24 Hamburg, Germany, 2010

[9] Maldague X. P. V., "Theory and Practice of Infrafred Technology for Nondestructive Testing", John Wiley \& Sons, Inc., New York, 2001

[10] ASTM E976: "A Standard Guide for Determining the Reproducibility of Acoustic Emission Sensor Response", American Society for Testing and Materials, 1994

[11] Surgeon M., Wevers M., "Modal analysis of acoustic emission signals from CFRP laminates", NDT \& E International, vol. 32, pp. 311-322, 1999 
[12] Levin K., Nilsson S., "Examination of reliability of fibre optic sensors embedded in carbon/epoxy composites" Proc. SPIE 2779, pp. 222-231, 1996

[13] Riccio A., di Caprio, F., Camerlingo F., Scaramuzzino F., Gambino B., "Positioning of Embedded Optical Fibres Sensors for the Monitoring of Buckling in Stiffened Composite Panels" Applied Composite Materials, February 2012

[14] Voto C., Inserra S., Camerlingo F. P., Iodice M., Rendina I., "Fiber optic strain sensors: Aerospace applications and requirements", Proceedings of the First European Workshop for Structural Health Monitoring, Paris 10-12 July 2002, pp.861-868, D. L. Balageas Ed., Destech Publications, 2002

[15] Sirkis J. S., Dasgupta A., "Optical fiber/composite interaction mechanics", Fiber Optic Smart Structures, pp. 61107, E. Udd Edition, Wiley, New York, 1995.

[16] Meola C., Carlomagno G.M., "Infrared thermography in non-destructive inspection: theory and practice", Recent Advances in Non Destructive Inspection, pp. 89-123, Meola C. Ed., Nova Science Publisher Inc., 2010

[17] Busse G., "Lockin thermography in Nondestructive in Testing Handbook". Infrared and Thermal Testing, vol. 3, pp. 318-327, Maldague X. Ed., American Society for Nondestructive Testing Inc., Columbus, OH, 2001

[18] Meola C., Carlomagno G.M., Squillace A., Vitiello A., "Nondestructive Evaluation of Aerospace Materials with Lockin Thermography", ICEFA-I First International Conference on Engineering Failure Analysis, Lisbon, Portugal, 2004

[19] http://www.cocomat.de/Endmeeting/Abstracts/13-DLR_Degenhardt.pdf

[20] Riccio A., Perugini P., Scaramuzzino F., "Embedded Delamination Growth In Composite Panels Under Compressive Load", Composites part B: Engineering, vol. 32/3, pp. 209-218, April 2001. ISSN: 1359-8368

[21] Riccio A., Pietropaoli E., "Modelling damage propagation in composite plates with embedded delamination under compressive load", Int. Journal of Composite Materials, vol. 42, n.13, pp. 1309-1335, 2008.

[22] Pietropaoli E., Riccio A., "Formulation and assessment of an enhanced finite element procedure for the analysis of delamination growth phenomena in composite structures", Composite Science and Technology, 71 (6), pp. 836-846, 2011

[23] Pietropaoli E., Riccio A., " A Global/Local Finite Element Approach for Predicting Interlaminar and Intralaminar Damage Evolution in Composite Stiffened Panels Under Compressive Load", Applied Composite Materials, vol. 18, n. 2, pp. 113-125, Springer, 2011 